\title{
Creativity in Dyslexic Individuals
}

\section{Kateřina Šimčíková}

Department of Special and Inclusive Education, Faculty of Education, Masaryk University, Brno, Czech Republic

How to cite this paper: Šimčíková, K. (2018). Creativity in Dyslexic Individuals. The Educational Review, USA, 2(9), 458-467. http://dx.doi.org/10.26855/er.2018.09.001

Corresponding author: Kateřina Šimčíková, Mgr., Department of Special and Inclusive Education, Faculty of Education, Masaryk University, Brno, Czech Republic.

\begin{abstract}
The literature review analyzes seven specialized papers, which are focused on issues of increased creativity of individuals with dyslexia. In connection with dyslexia, it starts to talk not only about deficits, but also about its possible positives, which develop in the context of possible weaknesses. In individuals with dyslexia are mentioned excellent visualization skills and increased creative potential. Based on some results of foreign research studies was proven a significantly higher level of creativity in persons with dyslexia in comparison with intact individuals in the group of adults with an average age greater than 18 years. Significantly higher level of acquired scores was not proven in children with dyslexia. It can be concluded that people with dyslexia have undoubtedly a specific creative potential.
\end{abstract}

\section{Keywords}

Dyslexia, Creativity, Positive Aspects, Literature Review, Originality of Thinking, Dyslexic Individuals, Intact Individuals

\section{Introduction}

Dyslexia is a set of specific symptoms that is hard to grasp and rather difficult to define. It exists on a scale of severity and influences an individual in different ways (Morgan \& Klein, 2000). We understand dyslexia as a combination of abilities and difficulties which affect an individual in the process of learning how to read, write and in some cases count (although their intellectual abilities are normal and independent of the language and socioeconomic environment). Dyslexia manifests itself by weakening the speed of mental processes, sequential analysis, short-term memory, visual and/or auditory perception, speech and motoric skills (Peer in Zelinková, 2012).

Dyslexia brings its bearers complications throughout their lives or at certain stages of development; however, besides its generally known deficits, dyslexia can also bring some positive aspects as well. As stated by Davis \& Braun (2010), dyslexia definitely does not turn every person into a genius, but having trouble reading, writing, spelling or counting does not have to mean one is stupid. The following is a list of the basic abilities of all dyslexics as compiled by Davis \& Braun (2010): they can utilize the brain's ability to alter and create perceptions (the primary ability); they are highly aware of the value of their environment; they are more curious than average people; they think mainly in pictures instead of words; they are highly intuitive and insightful; they think and perceive multi-dimensionally (through all the senses); they have vivid imaginations and can experience thought as reality. These eight abilities (if they are not suppressed, dismissed or ruined by parents or the process of education) will present themselves with two characteristics - higher intelligence and exceptional creative abilities. Talents and giftedness may manifest themselves in various forms and areas. There are, however, certain general characteristics that dyslexics usually share, those being non-verbal thinking, developed intuition and a rich creative potential. Dyslexic individuals have, in comparison to intact individuals, much stronger creative urges and the creativity of dyslexics increases due to thinking in im- 
ages, intuitive thinking, multidimensional thinking and curiosity.

Creativity is a large area of a person's skills, which has been researched by multiple branches of science. There are a number of definitions for creativity. Each of the definitions maps this hard-to-grasp phenomenon differently. For instance, Runco (2007) regards creativity as a fundamental constituent of specifically human potential which adds to the information explosion and at the same time helps each of us adapt. Pokorný (2004) says about creativity that it is the opposite of the traditional thinking and rigid use of tested methods, the opposite of a mundane activity repeated by force of habit. Sternberg (2009) states that creativity is the process of creating something original and valuable. "Creativity is often defined as originality which is adjusted to fit a problem and, at a certain point in time, suitable for a particular group of people" (Svoboda, 1999, p. 95). "We can characterize creativity as a comprehensive skill which is the result of a successful synthesis of one's personality, cognitive abilities and other motives" (Plháková, 2004, p. 294).

Creativity is an ability that can be developed. A certain level of hypothetical creative abilities is characteristic for every person, even though many authors allow for the possibility that some individuals can be more creative than others. Lately, specific abilities of dyslexics have been talked about more and more, not only in connection to the widely accepted deficits and symptoms. The usually stated specific abilities of dyslexics are the following: the ability of insight, excellent visualization abilities, logical thinking and innovative approach to problem solving, and increased level of creativity in everyday life as well as in professional and artistic activities (Bartlett \& Moody, 2000; Dacey \& Lennon, 2000; Davis \& Braun, 2010; Everatt, 1997; Everatt, Steffert, \& Smythe, 1999; West, 2008; Wolff \& Lundberg, 2002).

\section{Methodology}

The review study deals with the issue of the so-called positive aspects of dyslexia, particularly the increased creativity of dyslexics. We have defined two thematic criteria for the selection of studies which are suitable for this analysis: dyslexic individuals and creative thinking. We tried to grasp the chosen review study topic comprehensively. The following research questions were asked during the analysis: What is the level of creativity in dyslexic individuals? Is there a difference in the level of creativity between dyslexic and intact individuals? What can influence the level of creativity in dyslexic individuals? Is there a significant differentiation in any area between dyslexic and intact individuals?

With this objective in mind, seven scientific papers dealing with the topic of interest were selected according to the chosen parameters and subsequently analyzed. Collecting and studying scientific literature of foreign origin took place in 2017. The titles for the review study were looked up in the Web of Science, ERIH and Scopus databases. The selection was limited to available full-text sources accessible online. We focused on thematic papers from the twenty-year period between the years 1997 - 2016. On the basis of the set criteria for selecting suitable texts and the performed analysis, the findings from relevant studies were synthesized into a review study. This paper attempts to analyze the individual selected papers in a systematic review, provide their brief description, differentiate and highlight their specifics, evaluate their usefulness for theory and practice and generally integrate the findings regarding increased creativity in dyslexics into this review study. The analyzed studies are listed in Table 1.

Table 1. Overview of the analyzed studies on the relationship between creativity and dyslexia.

\begin{tabular}{cccc}
\hline Title & Author, Year & Methodology & Research Results \\
\hline $\begin{array}{c}\text { The Abilities and Disabilities } \\
\text { Associated with Adult Devel- } \\
\text { opmental Dyslexia }\end{array}$ & Everatt, J., 1997 & Target and control group of & $\begin{array}{c}\text { Significant differences between } \\
\text { target and control group (higher } \\
\text { respondents. }\end{array}$ \\
scores in the creativity tests in \\
people with dyslexia), in other \\
areas differences between
\end{tabular}




\begin{tabular}{|c|c|c|c|}
\hline Title & Author, Year & Methodology & Research Results \\
\hline \multirow{6}{*}{$\begin{array}{l}\text { An Eye for the Unusual: Crea- } \\
\text { tive Thinking in Dyslexics }\end{array}$} & \multirow{6}{*}{$\begin{array}{l}\text { Everatt, J., Steffert, B., \& } \\
\text { Smythe, I., } 1999\end{array}$} & & groups were not found. \\
\hline & & $\begin{array}{l}\text { 1st research } \\
\text { Target and control group of } \\
\text { respondents. } \\
\text { Test tasks. } \\
18 \text { people with dyslexia and } 18 \\
\text { intact people. } \\
\text { 2nd research }\end{array}$ & $\begin{array}{l}\text { Increased creativity is probably } \\
\text { not dependent on the severity of } \\
\text { the lateral hemisphere of the } \\
\text { brain or the degree of individual } \\
\text { visual and spatial abilities. }\end{array}$ \\
\hline & & $\begin{array}{l}\text { Qualitative method. } \\
\text { Testing by KAI (Kirton Adap- } \\
\text { tion-Innovation Inventory). } \\
14 \text { people with dyslexia and } 20 \\
\text { intact people. }\end{array}$ & $\begin{array}{l}\text { Students with dyslexia achieved } \\
\text { significantly higher scores than } \\
\text { the control group, indicating } \\
\text { their more innovative tendency. }\end{array}$ \\
\hline & & $\begin{array}{l}\text { 3rd research } \\
\text { Five situations associated with } \\
\text { manipulation of shapes or fig- } \\
\text { ures. } \\
16 \text { people with dyslexia and } 23 \\
\text { intact people. }\end{array}$ & $\begin{array}{l}\text { Problem tasks - higher success } \\
\text { rates of people with dyslexia } \\
\text { than their intact counterparts. } \\
\text { The "hidden figures" test did } \\
\text { not show a reliable relationship } \\
\text { between creativity and addic- } \\
\text { tion in adults. }\end{array}$ \\
\hline & & $\begin{array}{c}\text { 4th research } \\
\text { Qualitative method. } \\
37 \text { pupils with dyslexia and } 42 \\
\text { intact pupils. }\end{array}$ & $\begin{array}{l}\text { It did not show a difference } \\
\text { between the target and the } \\
\text { comparator group. }\end{array}$ \\
\hline & & $\begin{array}{l}\text { 1st research } \\
\text { Quantitative method, question- } \\
\text { naire - screening of dyslexia } \\
\text { and author's West method - } \\
\text { phonological skills testing. } \\
74 \text { students of the Faculty of } \\
\text { Arts and } 80 \text { students of the } \\
\text { Faculty of Economic Studies } \\
\text { and Law. }\end{array}$ & $\begin{array}{l}\text { Symptoms of dyslexia were } \\
\text { reported by } 11 \text { students of arts } \\
\text { and } 1 \text { student of economic } \\
\text { studies and law. } \\
\text { Students of arts showed signif- } \\
\text { icantly more dyslexic symptoms } \\
\text { and had worse phonological } \\
\text { skills than students of other } \\
\text { fields. }\end{array}$ \\
\hline $\begin{array}{l}\text { Profiles of Strengths and } \\
\text { Weaknesses in Dyslexia and } \\
\text { Other Learning Difficulties }\end{array}$ & $\begin{array}{l}\text { Everatt, J., Weeks, S., \& } \\
\text { Brooks, P., } 2008\end{array}$ & $\begin{array}{l}\text { Quantitative method. } \\
83 \text { pupils with different special } \\
\text { educational needs and } 40 \text { intact } \\
\text { pupils. }\end{array}$ & $\begin{array}{l}\text { Pupils with dyslexia have } \\
\text { achieved significantly lower } \\
\text { scores for both language tasks, } \\
\text { but in most non-verbal tasks } \\
\text { they have achieved the same or } \\
\text { better performance than the } \\
\text { intact pupils. }\end{array}$ \\
\hline $\begin{array}{l}\text { Art Students Who Cannot } \\
\text { Draw: Exploring the Relations } \\
\text { Between Drawing Ability, Vis- } \\
\text { ual Memory, Accuracy of Cop- } \\
\text { ying, and Dyslexia }\end{array}$ & $\begin{array}{c}\text { McManus, I. C., Chamberlain, } \\
\text { R., Loo, P. W., Rankin, Q., } \\
\text { Riley, H., \& Brunswick, N., } \\
2010\end{array}$ & $\begin{array}{c}\text { 1st research } \\
\text { Quantitative method - ques- } \\
\text { tionnaire. } \\
\text { 277 students (187 postgraduate } \\
\text { students of art and } 90 \text { students } \\
\text { of proper study). } \\
\text { 2nd research } \\
\text { Qualitative method. } \\
\text { A target group of } 38 \text { art stu- } \\
\text { dents and a control group of } 30\end{array}$ & $\begin{array}{c}\text { The results of self-assessment } \\
\text { in the drawing showed ambigu- } \\
\text { ity and did not relate to dyslex- } \\
\text { ia. } \\
37 \text { students were diagnosed } \\
\text { with dyslexia. } \\
\text { The results do not indicate cor- } \\
\text { relation in the test of correct } \\
\text { word recording and drawing } \\
\text { assessment, nor the differences }\end{array}$ \\
\hline
\end{tabular}




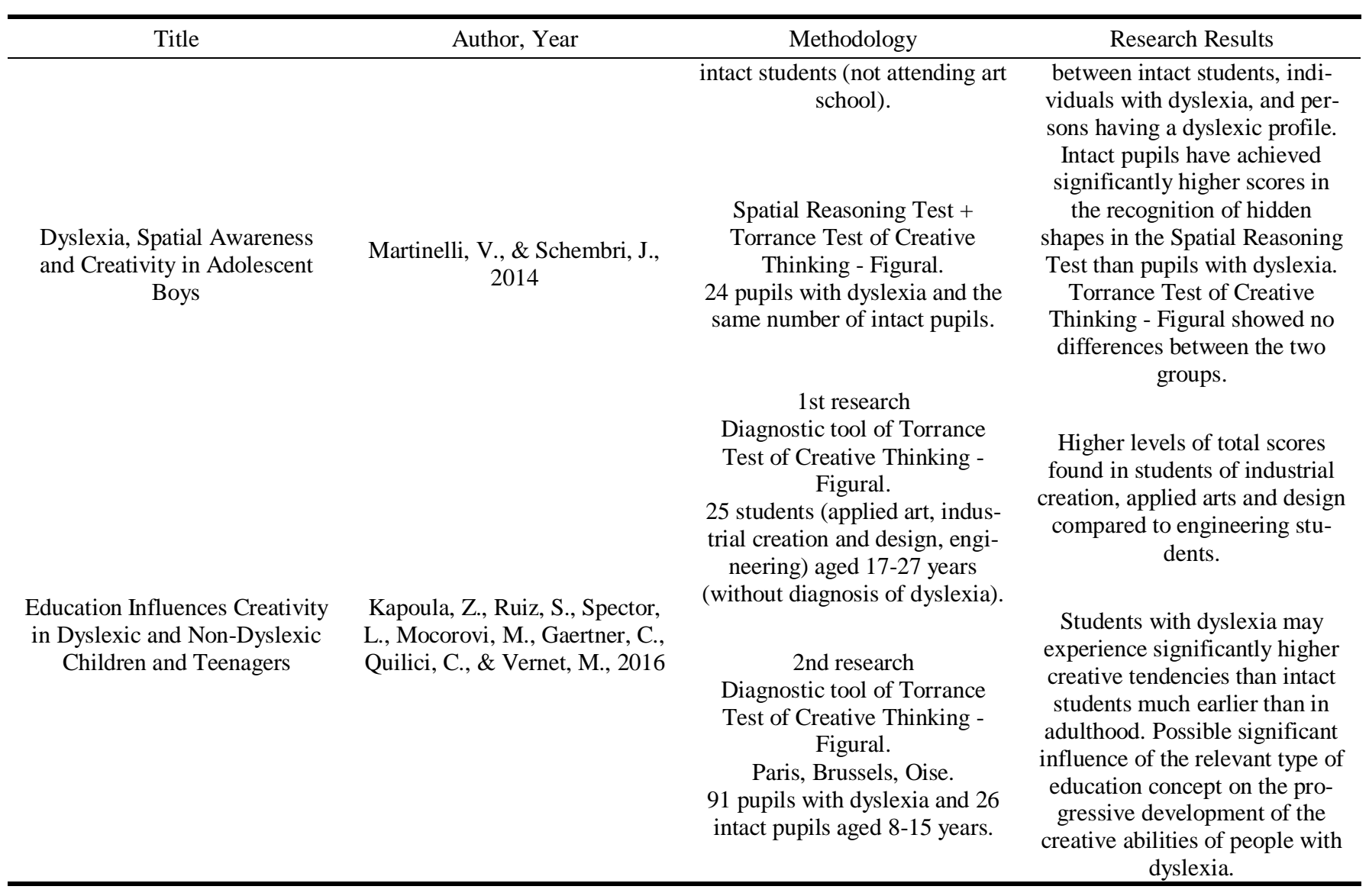

\section{Results of the Review}

In his research, Everatt (1997) focused on differences in results observed in testing the creativity of thinking in dyslexic individuals. The test group was comprised of volunteers whose intelligence was expected to be within or above the average for the age group 18-49, the ratio of men to women was comparable in the groups of respondents with and without dyslexia. The dyslexic individuals were selected on the basis of reliably diagnosed dyslexia; the intact individuals were selected from the general population, mostly university students. Both the groups participating in the research underwent a test of processing words in the context of auditory synthesis, which includes for instance writing to dictation, comprehension, fast naming with interference, spatial ability and creativity, and it included both figural and verbal tasks. The results of the research study showed a significant difference between the control and target group, with dyslexics tending to score higher in creativity tests; there were no clear differences between the groups in other areas.

In their research, Everatt, Steffert \& Smythe (1999) followed up on the previous study; they processed and compared the results of four new studies regarding creativity of dyslexics and the relationship between dyslexia and creative talent.

The first study deals with the creativity in thinking of dyslexics; it builds on the previous research study (Everatt, 1997) and copies the drawing and verbal tasks used in the previous tests. The test group was comprised of the target and control groups of 18 adult individuals with dyslexia and 18 intact individuals respectively. All the participants were university students. The respondents had two tasks to complete. The first task presented a figural problem which depicted a combination of simple shapes forming an object or concept. The participants were given a sheet of A4 paper with five shapes printed on it (square, oblong, triangle, circle and quadrilateral) and were asked to create a drawing using these shapes re- 
peating them as they liked. While giving instructions, it was stressed that using the same items would not increase the number of points they would get. This task had a time limit of six minutes. The second task was to invent as many altern ative uses of everyday objects as possible and the time limit was four minutes. It was pointed out to the participants that identical and irrelevant answers would not be taken into consideration. The instructions to both tasks were given orally to avoid putting the dyslexic group at a disadvantage. The secondary goal was to test the level of visuospatial skills of the control and target groups through the set of two tasks. The result again confirms a significantly higher score level of dyslexic individuals in the test tasks focused on creative thinking; on the other hand, no significant difference in visuospatial skills of the groups was confirmed. From the obtained results, it can be concluded that increased creativity is probably not connected with strong laterality of brain hemispheres or with the level of individual visuospatial skills (Everatt, Steffert, \& Smythe, 1999).

The second research included 14 people with dyslexia and 20 intact art students. These individuals were tested using the KAI (Kirton Adaption-Innovation Inventory) method, which contains 33 questions (one is not given points for) for which answers are chosen on a five-point scale. The whole test is comprised of three subscales - the "originality" subscale with 13 items, the "group conformity" subscale with 10 items and the "efficiency" subscale with the remaining 9 items. Individual creativity is not measured from the viewpoint of creativity level, but on the basis of the form of the creative behavior style, the "creativity type" is evaluated in the range between two poles: "innovative" - "adaptive" type (Hayward \& Everett, 1983; Kirton, 1976; Shiomi \& Loo, 1999). The method maps creativity through subjective assessment of certain problem solving strategies and individual cognitive styles. The KAI method was selected for its high correlation with other methodological means studying the same field and for its high reliability and validity. Dyslexics were tested separately, intact students, on the other hand, collectively. KAI was presented on one sheet of A4 paper and the answers were offered on the five-point scale from "very difficult" to "very easy". The administration or work on the task itself had no time limit. In this research, dyslexic students scored significantly higher in comparison to the control group of intact students, which shows their more innovative inclination (Everatt, Steffert, \& Smythe, 1999).

The third research was based on the specifics of creative problem solving and innovative styles of inventing solutions. The participants of this study were university students, 16 dyslexic individuals and 23 intact individuals. The exact purpose of the research was not disclosed to the participants. The scope of creative problem solving was five situations which were connected to manipulating shapes or figures (none of them required literacy). They were the following types of problems: to connect nine points with four straight lines without lifting the pen, create arrangement B from arrangement A by moving no more than three circles, to draw a fifth figure in line, to divide a particular shape into four equally sized parts of the same shape, to connect individual points of a chain in such a way to make it possible to split it or close it using only three links. The figural problems were presented on a sheet of A4 paper and contained a total of 24 drawings which included shapes of familiar objects. The respondents were asked to find as many of the individual pictures hidden in the drawings as possible in the time limit of five minutes and circle them in pencil. The summary of the results of the "problem-solving tasks" showed a higher rate of success in dyslexics in comparison to their intact counterparts. The "hidden figure" test did not show a reliable correlation between dependence and creativity in adult subjects or a significant link between the ability to locate embedded figures and creativity (Everatt, Steffert, \& Smythe, 1999).

The fourth study involved 17 pupils with dyslexia and the same number of intact pupils aged 7-9, and 20 pupils with dyslexia and 25 intact pupils aged 11-13. They were paired with regards to their age, gender identity, presence or absence of dyslexia and their level of intellectual abilities, which had been determined in advance by using the Wechsler Intelligence Scale for Children (WISC). The objective of the research was to assess how original the pupils' drawings were. The pupils were tested in smaller groups. A preceding analysis of standard drawings did not show a significant difference in original- 
ity between the control and target groups. Within the data collection in this research, the pupils got oral and written instructions and 15 minutes to complete the task. Two independent assessors then classified the originality of the drawings on a five-point scale while considering also the number of drawings produced within the time period. The research results did not show a difference between the control and target group regardless of whether creativity was assessed on the basis of the number of drawings produced or the originality score received (Everatt, Steffert, \& Smythe, 1999).

Wolff and Lundberg (2002) focus on the possible correlation of artistic talent and dyslexia. They conducted two studies mapping the manifestations of dyslexia through subjective perception, the quality of phonological skills and word recognition.

The first study involved 80 students (43 women, 37 men) from the Faculty of Economic Studies and Law at the University of Gothenburg in Sweden and 74 students (34 women, $40 \mathrm{men}$ ) from two art faculties at the same university. The main objective of the research was to determine the potential number of dyslexic individuals in both groups. A screening of dyslexia symptoms was performed through a questionnaire which focused on practical problems with writing and reading, motivation to do activities related to literacy. Individual items were rated by the respondents on a scale of four points. The word recognition test was based on a chain of words which linked three familiar words. The task was to correctly divide these words with pencil lines. The final score corresponded to the sum of words correctly divided within the time limit of three minutes. The author recognition method modelled after West was used to test phonological skills, specifically to determine the level of reading skills and of the ability to recognize printed words. The final score was based on the number of correctly read words minus the number of mistakes. The results of the research suggested that there were 11 people (three women, eight men) with dyslexia symptoms in the group of art students and only one woman in the group of economy and law students. The art students showed significantly more dyslexia symptoms and also had considerably lower phonological skills in comparison to the control group of students from other fields (Wolff \& Lundberg, 2002).

The second study was conducted with 194 art students (148 women, 46 men) studying in graduate programs at the University of Gothenburg, namely architecture, design or crafts. These were compared to 202 students (98 women, 104 men) of non-art programs, such as economy, psychology, politics. The average age of both groups was about 26 . The methods used in this study were modifications of the previous study. The questionnaire contained 29 items; the word recognition test was used in the same manner as in the previous study. The last method used was a phonological choice test. All correctly recognized words were counted in the time limit of two minutes. The research study did not show a significant difference in results between the genders. After processing, the data revealed 44 art students and 17 non-art students meeting the criteria for dyslexia. However, the authors of the study speculate that this sum is, due to the number of respondents in the test group, significantly higher than the commonly stated incidence of dyslexia in the entire population. In the auditory word recognition test, the results suggest that 5 art students and 17 non-art students reached a score implying dyslexia. The results of the phonological choice test indicated nine art students and two non-art students as potential dyslexics (Wolff \& Lundberg, 2002).

Everatt, Weeks \& Brooks (2008) conducted research into the strengths and weaknesses of pupils with special educational needs (dyslexia, dyspraxia, attention deficit disorders, behavioral and emotional disorders, etc.). A total of 83 pupils aged 11-13 years with different special educational needs were compared with 40 intact pupils (without specific learning difficulties) of the same age based on their performance in the tests. All pupils were then tested in writing, reading, verbal and phonological skills, nonverbal abilities (reasoning, creativity, spatial memory and visomotor coordination), attention and related behavioral factors. Creativity has been tested through a number of shapes, from which the pupil gradually assembled and drew as many objects as possible. If the object was hardly recognizable, the disciple was asked to name it. The results of a research study suggested that people with dyslexia achieved significantly lower scores compared to the group 
of intact people in both language tasks, but in most non-verbal tasks persons with dyslexia achieved the same or better performance than intact persons.

McManus, Chamberlain, Loo, Rankin, Riley \& Brunswick (2010) dealt with self-assessment and performance of art students both ones with dyslexia symptoms and intact ones. Many students describe typical dyslexia related issues. The self-assessment of these students, also based on negative experience, is often much lower than their actual performance. Two research studies were realized to map this situation.

277 students participated in the first research. The test subjects were divided into two groups: 90 foundation students (63 women, 27 men, aged 19-20) and 187 postgraduate art students (103 women, 84 men, aged 25-29) at Swansea Metropoli$\tan$ University. The students filled in a questionnaire covering nine areas: skills, aesthetic activities, lateralization, right-left confusion, dyslexia, spelling test, personality, education, demographics. The results of the self-assessment of their own drawing highlighted its ambiguity and they were in no way related to dyslexia. The self-assessment of art students regarding their own drawings was considerably different even though there was no significant difference shown in relation to other tested areas. 37 students were confirmed dyslexic, another 55 students had predisposition to this diagnosis. It was also shown that a history of dyslexia correlated with a history of stuttering, a family history and also worse academic results, while low scores in correct spelling corresponded with lower grades in "literature" (McManus, Chamberlain, Loo, Rankin, Riley, \& Brunswick, 2010).

The second study evaluated the ability to draw in a group of students divided by their marks in drawing and in a spelling test in comparison to a control group of non-art students whose drawing skills were assumed to be on a similar level as for the group of "poor drawers". The study was realized in order to find a correlation of poor drawing skills and dyslexia. The test group was comprised of 38 art students whose native language was English. 16 students were labelled as "good drawers" and 22 students as "poor drawers". The control group was comprised of 30 intact students who did not attend an art school. The testing took place in groups of four to eight with the total of eight tasks. Each task was presented on one sheet of paper and required the use of a pencil. The individual tasks were assessed by professionals and laymen (McManus, Chamberlain, Loo, Rankin, Riley, \& Brunswick, 2010).

Martinelli \& Schembri (2014) conducted research with 24 dyslexic pupils and the same number of intact pupils. The dyslexic individuals were selected on the basis of having been diagnosed with dyslexia, same age (average age 12 years and 10 months), school type and similar socioeconomic status. The participants were given the Torrance Test of Creative Thinking - Figural (TTCT-F) and a Spatial Reasoning Test. The intact pupils reached significantly higher scores in recognizing hidden shapes in the Spatial Reasoning Test than the dyslexic pupils. TTCT-F did not show any difference between both groups of pupils. It is necessary in this context to point out the strong impact of the educational concept of a given school type.

Kapoula, Ruiz, Spector, Mocorovi, Gaertner, Quilici \& Vernet (2016) focused on determining the level of creative skills in students with dyslexia and other associated learning issues and intact students of different ages. The first research studied a group of adult students at three universities in Paris which try to support different kinds of creativity at the programs they offer, specifically nine students of applied art, eight students of mechanical engineering and eight students of industrial creation and design. The test group was comprised of participants aged 17-27 not diagnosed with dyslexia. The second research aimed at children and teenagers at three schools in Belgium and France which educate pupils with dyslexia and offer them special modified study programs. The children and teenagers were included in the research after undergoing comprehensive dyslexia diagnostics. That involved determining the level of reading skills, writing, attention and memory and there was a requirement for the participants to have standard intellectual abilities. Thus the research included dyslexic pupils, pupils with other associated learning issues and intact pupils aged 8-15, specifically Paris 11-14, Brussels 12-15, 
Oise 8-12. The test group was comprised of 91 pupils (27 girls, 64 boys) with dyslexia or other associated learning issues and 26 pupils (14 girls, 12 boys) from the intact part of population. The research used the Torrance Test of Creative Thinking - Figural (TTCT-F) as a diagnostic tool.

The results of the first research show higher levels of determined scores and individual elaboration scores in the mechanical engineering students in comparison to the applied art and industrial creation and design students. In the second research, the dyslexic students in Brussels got statistically better results in all the areas monitored by TTCT-F compared to the control group of intact pupils. The total scores of the dyslexic pupils and the pupils with associated learning issues were not significantly different throughout the test group. A comparison of the three schools showed, with statistical significance, that the dyslexic pupils in Brussels had better results than those in Paris; at the same time, they pointed out the almost equal results of the individual pupils. The dyslexic participants in Oise also scored statistically significantly higher than the dyslexic pupils in Paris, except in the area of elaboration. None of the areas monitored by TTCT-F was significantly different for the dyslexic pupils in Oise and Brussels (Kapoula, Ruiz, Spector, Mocorovi, Gaertner, Quilici, \& Vernet, 2016).

The comparison of the most creative groups of dyslexic pupils in Brussels and art students at a university in Paris brought several findings. The Belgian dyslexic students reached significantly higher scores in flexibility compared to the art students. The area of elaboration brought the opposite situation when the art students reached significantly higher scores in elaboration in comparison to the Belgian pupils. A comparison of these groups did not show any considerable differences in the areas of originality and fluency. Almost a third of the students claimed learning issues comparable to dyslexic individuals (reading difficulties, mixing-up letters, attention deficits, etc.), even though they had never been diagnosed. Certain creative potential in dyslexics can be purposely supported and developed also in relation to a given enforced educational approach (Kapoula, Ruiz, Spector, Mocorovi, Gaertner, Quilici, \& Vernet, 2016).

\section{Conclusion}

The administered tests presenting tasks which required new approaches and subsequent innovative solutions showed a significantly higher level of creative thinking in adult dyslexics. No significant difference in scores of dyslexic children and intact children was shown. The authors used these findings to start a discussion whether the higher level of creativity shown in adult dyslexics is the result of increased speed of the right brain hemisphere, or whether the higher creative potential is naturally typical of these individuals. At the same time, however, no clear proof that creativity correlates with visuospatial skills or with laterality was discovered (Everatt, 1997; Everatt, Steffert, \& Smythe, 1999).

A higher incidence of dyslexia symptoms was shown in art students in comparison to students of other non-art programs. The authors critically pointed out that the higher incidence of dyslexia symptoms in art students cannot be explained causally. The inquiry was correlational and therefore does not allow causal conclusions to be drawn. There are reasons to believe that choosing a graduate art program does not reflect an attempt to avoid higher requirements of traditional academic programs; we can interpret the obtained results as an actual choice based on extraordinary talent with regards to the fact that such talent is often discovered very early in dyslexics before they experience school environment and learn how to read and write. In this context, the connection between dyslexia and artistic talent could be considered real (Wolff \& Lundberg, 2002).

The higher score of "poor drawers" in the overall results compared to the control group indicates certain skills in this area. The results also suggested a tendency towards worse self-assessment in the "poor drawer" group as compared to their actual performance. On the other hand, no correlation was shown between the word recognition test and drawing evaluation, and there was no considerable difference between the intact individuals, dyslexic students and individuals with dyslexic issues. The partial results of the scores for the three tasks did not confirm a potential correlation, e.g. there was not a single case with a signif- 
icant difference between the control group, the group of "good drawers" and the group of "poor drawers" for the Rey-Osterrieth Figure. The overall results of the research studies did not show a significant correlation between a low level of drawing skills and dyslexia (McManus, Chamberlain, Loo, Rankin, Riley, \& Brunswick, 2010).

The strong side of people with dyslexia appears to be their ability in the tasks of visual-spatial memory, as compared to their weakening in reading, writing and phonological processing. The difference in the higher levels of scoring found in the creativity of people with dyslexia is not found in a group of children (pupils and students), while in adults with dyslexia, significant differences between groups are already described (Everatt, Weeks, \& Brooks, 2008; Martinelli \& Schembri, 2013).

Dyslexics can be almost as creative as art students selected for their creativity. On the basis of their results, the authors speculate that dyslexic pupils and students may manifest significantly higher creative tendencies in comparison to intact pupils and students much earlier than in adulthood. At the same time, they point out a possible influence of a given educational concept on the gradual development of creative skills in dyslexics (Kapoula, Ruiz, Spector, Mocorovi, Gaertner, Quilici, \& Vernet, 2016).

Research studies into the incidence of dyslexic symptoms in people with high creative potential and research studies directly comparing the level of creativity of individuals with dyslexia and intact individuals have generally yielded consistent conclusions suggesting that individuals with dyslexia have the ability to develop creative thinking exceeding intact individuals. Individuals with dyslexia therefore undoubtedly have a specific creative potential. These exceptional creative abilities of individuals with dyslexia can then be seen as a successful compensation strategy due to particular difficulties, especially as a separate area of individual talent development.

\section{References}

Bartlett, D., \& Moody, S. (2000). Dyslexia in the Workplace. London: Whurr.

Dacey, J. S., \& Lennon, K. H. (2000). Kreativita. Praha: Grada.

Davis, R. D., \& Braun, E. M. (2010). The Gift of Dyslexia: Why Some of the Smartest People Can't Read ... and How They Can Learn. New York: Perigee Trade.

Everatt, J. (1997). The Abilities and Disabilities Associated with Adult Developmental Dyslexia. Journal of Research in Reading, 20(1), $13-21$.

Everatt, J., Steffert, B., \& Smythe, I. (1999). An Eye for the Unusual: Creative Thinking in Dyslexics. Dyslexia: An International Journal of Research and Practice, 5(1), 28-46.

Hayward, G., \& Everett C. (1983). Adaptors and Innovators: Data from the Kirton Adaptor-Innovator Inventory in a Local Authority Setting. Journal of Occupational Psychology, 56(4), 339-342.

Kapoula, Z., Ruiz, S., Spector, L., Mocorovi, M., Gaertner, C., Quilici, C., \& Vernet, M. (2016). Education Influences Creativity in Dyslexic and Non-Dyslexic Children and Teenagers. PLoS ONE, 11(3), 1-14.

Kirton, M. (1976). Adaptors and Innovators: A Description and Measure. Journal of Applied Psychology, 61(5), $622-629$.

Martinelli, V., \& Schembri, J. (2014). Dyslexia, Spatial Awareness and Creativity in Adolescent Boys. Psychology of Education Review, 38(3), 39-47.

McManus, I. C., Chamberlain, R., Loo, P. W., Rankin, Q., Riley, H., \& Brunswick, N. (2010). Art Students Who Cannot Draw: Exploring the Relations Between Drawing Ability, Visual Memory, Accuracy of Copying, and Dyslexia. Psychology of Aesthetics, Creativity, and the Arts, 4(1), 18-30.

Morgan, E., \& Klein, C. (2000). The Dyslexic Adult in a Non-dyslexic World. London: Whurr.

Pokorný, J. (2004). Myslet kreativně. Brno: CERM.

Runco, M. A. (2007). Creativity: Theories and Themes: Research, Development, and Practice. Boston: Elsevier Academic Press.

Shiomi, K., \& Loo, R. (1999). Cross-Cultural Response Styles on the Kirton Adaption-Innovation Inventory. Social Behavior and Personality: An International Journal, 27(4), 413-420.

Sternberg, R. J. (2009). Kognitivní psychologie. Praha: Portál.

Svoboda, M. (1999). Psychologická diagnostika dospělých. Praha: Portál. 
West, T. (2008). It Is Time to Get Serious About the Talents of Dyslexics. Perspectives on Language and Literacy, 34(3), 9-11.

Wolff, U., \& Lundberg, I. (2002). The Prevalence of Dyslexia Among Art Students. Dyslexia, 8(1), 34-42.

Zelinková, O. (2012). Dyslexie u studentů vysokých škol. Psychologie pro praxi, 47(1), 49-64. 